REVISÃO DE LITERATURA/BIBLIOGRAPHY REVIEWS

\title{
Doença Celíaca: Sintomas, Diagnóstico e Tratamento Nutricional
}

\section{Celiac Disease: Symptoms, Diagnosis and Nutritional Treatment}

Resumo A doença celíaca é uma intolerância sensível ao glúten a qual depende de um processo imunológico. Ela pode aparecer durante na infância ou a vida adulta, quando uma intolerância permanente ao glúten é desenvolvida. $\mathrm{O}$ índice de mortalidade no mundo em virtude dessa doença é aproximadamente duas vezes maior que o da mortalidade por outras causas, com um aumento que acontece predominantemente no primeiro ano depois do diagnóstico da enfermidade. A morte ocorre principalmente devido à presença de malignidades com linfoma intestinal. Pacientes com doença celíaca apresentam sintomas como diarréia, anorexia, desnutrição, distensão abdominal e perda de peso. A doença pode estar associada a inúmeras outras, tais como dermatite herpetiformis, osteoporose, epilepsia e diabetes mellitus tipo 1. No Brasil, a incidência é de um caso para cada 681 pessoas em todo o país. O diagnóstico é baseado nas características clínicas, testes sorológicos de anticorpos específicos e biópsia intestinal. O tratamento dos pacientes celíacos consiste na exclusão do glúten da dieta deles por toda a vida, corrigindo os diferentes graus de desnutrição, anorexia, desidratação, intolerâncias alimentares, carências de vitaminas e minerais. Considerando que o principal fator etiológico da doença celíaca é de natureza dietética, a adoção de práticas alimentares voltadas para a exclusão do glúten da dieta constitui medida profilática bastante eficaz. Assim, cabe particularmente ao profissional nutricionista elaborar e orientar a terapia dietética do paciente celíaco e corrigir deficit nutricionais, excluindo o glúten e derivados da sua dieta.

Palavras-chave: DOENÇA CELÍACA, OSTEOPOROSE, EPILEPSIA E DIABETES MELLITUS.

Aвstract Celiac disease is a sensitive intolerance to gluten which depends on an immunological process and can appear during the childhood or adult life, when a permanent intolerance to the gluten is developed. mortality rate is approximately two times higher than other cases, appearing frequently in the first year after diagnosis. The death happens mainly due to the presence of malice's with intestinal lymphoma. Patient with disease celiac they present symptoms as diarrhea, anorexia, malnutrition, abdominal distention and weight loss. Besides, celiac disease can be associated the countless ones other, such as dermatitis herpetyforms, osteoporosis, epilepsy and diabetes mellitus type 1. In Brazil, the incidence is one case per 681 people. The diagnosis is based on the clinical characteristics, tests serological of specific antibodies and intestinal biopsy. The treatment consists of gluten free diet that correct different malnutrition degrees, anorexia, dehydration, food intolerances, and vitamins/minerals deficiencies. Considering that the main etiological factor of $\mathrm{CD}$ is dietary origin, the adoption of food habits such as gluten free diet constitutes an effective prophylaxis. In conclusion, nutritionists should elaborate a dietary therapy in order to correct nutritional deficits, excluding definitively gluten and derivates of diet.

Keywords: Celiac disease, osteoporosis, EPILEPSy AND DiABETES MELLITUS. 


\section{INTRODUÇÃO}

A doença celíaca (DC) éuma intolerância sensível ao glúten. Pode aparecer durantea infância ou na vida adulta, quando uma intolerância permanente ao glúten é desenvolvida. Assim, os pacientes celíacos não podem consumi-lo. Até mesmo a ingestão deuma quantidade mínima de glúten pode causar danos intestinais e conduzir a uma variedade de sintomas, incluindo dor abdominal, perda de peso, diarréia, irritabilidade e complicações em longo prazo, como osteoporose, infertilidade e malignidade. ${ }^{1}$

A mortalidade por DC é aproximadamente duas vezes maior que a mortalidade por outras causas da população geral, com um aumento que acontece predominantemente no primeiro ano depois do diagnóstico da doença. As mortes são principalmente devido às malignidades intestinais. Um estudo feito por Cottone et al. ${ }^{2}$ com 228 adultos portadores de DC de uma população mediterrânea mostrou 12 mortes, 12 tumores e seis linfomas. 0 intervalo entre o diagnóstico da doença e a morte era de quatro anos. Em pesquisa realizada com uma população sueca constatou-se que 828 pacientes com DC morreram entre 1965 a 1994 com as seguintes malignidades: linfoma, câncer do intestino delgado, doenças autoimunes, como artrite reumática, doença difusa detecido conjuntivo, ou desordens alérgicas, como asma, infecção intestinal, diabetes mellitus, desordens de deficiência imune, tuberculose, pneumonia e nefrite. Observa-se risco de mortalidade elevado para todas as causas de morte combinadas, sendo a maior parte desordens caracterizadas por deficiência orgânica imune. ${ }^{3}$

A DC apresenta várias formas clínicas e, nos últimos tempos, as mais comuns são as atípicas, cujos sintomas geralmente passam despercebidos. Dentre os principais sintomas está a anemia por deficiência de ferro, além de artrites, osteoporose, esterilidade, constipação intestinal, retardo no crescimento e hipoplasia do esmalte dentário. 0 diagnóstico da DC é desafiador, pois as suas formas clínicas vêm se modificando e, cada vez mais, são latentes ou assintomáticas. Portanto, percebêlas exige o envolvimento não somente do gastroenterologista, mas também de vários outros profissionais da saúde. ${ }^{4}$

A coexistência da DC com outras doenças autoimunes, como o diabetes mellitus tipo 1, doença de Addison, lupus eritematoso sistêmico, artrite reumatoide, síndrome de Sjögren, hepatite autoimune, cirrose biliar primária e estomatite de repetição, tem sido relatada com frequência, sugerindo anormalidade intrínseca na regulação do sistema imune. A frequência da DC nos pacientes com doenças autoimunes da tireóide (DAT) tem se mostrado de quatro a oito vezes maior do que na população geral ou em doadores de sangue. ${ }^{5}$

0 diagnóstico dessa doença baseia-se em testes sorológicos (antiendomisial, antigliadina e anticorpos de antitransglutaminase) e em mudanças nas características histopatológicas (as vilosidades se atrofiam, hiperplasia das criptas e células inflamatórias infiltradas) visto em biópsia de duodenal distal, teste padrão para o diagnóstico da DC. ${ }^{6}$ De acordo com os critérios da Sociedade Européia e Latino- Americana, há necessidade de realizar três biópsias para fornecer o diagnóstico, sendo que a primeira delas revela atrofia vilositária, a segunda, logo após o tratamento que demonstra a recuperação das vilosidades e criptas, ea terceira eúltima que mostra um 
dano induzido pela dieta com glúten. Já com a dieta sem glúten observa-se rapidamente uma diminuição da lesão da mucosa intestinal e da má absorção com melhora sintomática. ${ }^{7}$

\section{Fisiopatologia}

O glúten é um polipeptídio existente no trigo (Triticum aestivum), centeio ( $\mathrm{Se}$ cale cerale), cevada (Hordeum vulgare) e aveia (Avena sativa). Seu efeito lesivo à mucosa intestinal na DC foi descrita por Dicke em 1950, na Holanda. 0 glúten constitui $90 \%$ das proteínas do endosperma do grão do trigo, subdivide-se em duas frações de acordo com a solubilidade: glutenina e gliadina. Esta, que geral mente corresponde a $50 \%$ da quantidade total do glúten, é solúvel em etanol a $70 \%$, enquanto quea glutenina é insolúvel em água e etanol a frio e ligeiramente solúvel em etanol a quente. Essas duas proteínas combinadas possuem a propriedade de formar, juntamente com a água, uma substância elástica e aderente, insolúvel em água, que éo glúten, extremamente importante, pois é responsável pela textura da massa de pães. As prolaminas são consideradas tóxicas ao celíaco e diferem de acordo com o tipo de cereal, sendo denominadas de gliadina no trigo, secalina no centeio, hordeína na cevada e avenina na aveia. ${ }^{8,9}$

Indiscutivelmente, foi demonstrada com exatidão a toxicidade da gliadina no intestino dos pacientes com DC, porém na aveia existem especulações quanto à sua fração tóxica, sendo necessários estudos mais conclusivos que suportem essa teoria. Ainda assim, recomenda-se a exclusão da aveia da dieta do paciente celíaco. ${ }^{10}$

0 mecanismo exato pelo qual o glúten danifica o intestino delgado ainda é desconhecido, entretanto os pressupostos recaem sobre os mecanismos genéticos, imunológicos e ambientais. A ingestão dessas proteínas por pessoas geneticamente predispostas induz uma lesão severa à mucosa intestinal, que se caracteriza por uma hiperplasia das criptas com atrofia total ou subtotal das vilosidades intestinais. ${ }^{11,12}$

Os danos causados às vilosidades intestinais levam a inúmeras deficiências, uma vez que os nutrientes são absorvidos em diferentes partes do trato gastrointestinal. 0 ferro, o cál cio e as vitaminas hidrossolúveis são absorvidos no duodeno e jejuno, assim como os lipídios e os açúcares também são absorvidos no jejuno. Os aminoácidos são absorvidos principalmente no jejuno, enquanto a vitamina $B_{12}$, vitamina $C$ e os sais biliares são absorvidos no íleo. A hidrólise de lipídios ocorre predominantemente no duodeno, embora também ocorra hidrólise no estômago. ${ }^{13}$

Sendo assim, para que ocorra a expressão da DC, além da exposição ao glúten na dieta, é necessária a presença de fatores genéticos, imunológicos e ambientais. ${ }^{14}$

\section{FAtores Genéticos}

Os fatores genéticos contribuem para o desenvolvimento da DC. Sua prevalência ocorre em parentes de primeiro grau, em cerca de $10 \%$. A concordância em gêmeos monozigóticos é de aproximadamente $75 \%$. Irmãos que compartilham o mesmo antígeno de histocompatibilidade (H LA) possuem concordância de $30 \%$ da DC. Esta apresenta forte associação com os alelos HLA DQB1*0201, DQA $1 * 0501$ e DRB1*0301. Aproximadamente $86 \%$ dos pacientes com DC apresentam os alelos H LA DQB1*0201 e DQA $1 * 0501$. A genotipagem do antígeno de histocompatibilidade (HLA) para 
DQB1*0201, DQA1*0501 e DRB1*0301 pode oferecer informações clinicamente úteis nas seguintes condições: na triagem para pacientes com pais portadores de DC e quando não é possível fazer um diagnóstico por causa da presença de resultados imunológicos e histológicos ambíguos. ${ }^{15,16,17}$

\section{FATORES IMUNOLÓGICOS}

Observa-se também um aumento no número de linfócitos, particularmente na atividade TCD4+, plasmócitos, específicos na lâmina própria da mucosa intestinal, em doentes celíacos. Além disso, evidencia níveis aumentados de anticorpos séricos e da mucosa contra a gliadina e aumento dos anticorpos séricos contra antígenos diferentes da gliadina. ${ }^{17}$

\section{FAtores Ambientais}

Certos fatores infecciosos estão envolvidos no desenvolvimento da $D C$. Dentre eles, 0 adenovírus sorotipo 12, principalmente uma de suas proteínas E1B, pode mostrar a sequência infecciosa viral e subsequente exposição à gliadina. Tais fatores poderiam desencadear o desenvolvimento da enteropatia como resultado de uma reação da atividade imunológica cruzada. ${ }^{18}$

\section{MANifestaÇões da Doença Celíaca}

A DC é uma das causas mais frequentes de má absorção intestinal na infância. Ela decorre, em grande parte, em função de uma intolerância intestinal permanente à gliadina. $\mathrm{Na}$ biópsia intestinal observa-se uma atrofia grave nas vilosidades intestinais. ${ }^{19} \mathrm{As}$ características clínicas da DC diferem consideravelmente em função da idade de apresentação da doença. Ainda assim, a diarréia e a má nutrição são comumente observadas.

As suas manifestações clínicas surgem habitualmente na infância, podendo ou não acometer na adolescência, vindo a reaparecer mais tarde após os 30 ou 40 anos. 0 principal acometimento dessa doença éa má absorção intestinal, incluindo sintomas comuns como perda de peso, fadiga, flatulência e diarréia associada com esteatorréia. Os celíacos podem apresentar glossites, estomatites, deficiência no esmalte dentário, má absorção de cálcio e vitamina $D$, síndromes neurológicas, infertilidade, osteoporose e anemia. ${ }^{20}$

A forma clássica ocorre geralmente entre seis e dezoito meses de idade, a qual é tipicamente caracterizada por diarréia crônica, anorexia, distensão abdominal, retardo no desenvolvimento e atrofia da musculatura glútea. 0 crescimento é normal durante o período em quea criança é amamentada exclusivamente no peito, porém os sintomas podem surgir entre semanas e meses após o desmame e a introdução de alimentos contaminados com prolaminas (gliadina, secalina, hordeína e avenina), e logo há uma diminuição progressiva dos pés, novamente com declínio nos percentis de e peso por estatura. No exame clínico pode-se notar que a criança apresenta palidez, com notável distensão abdominal, diminuição de gordura subcutânea e redução da massa muscular. As fezes apresentam característica pálida, aquosa, volumosa e fétida, devido à má absorção de gordura. $\mathrm{Na}$ infância, com o início dos sintomas, pode haver diarréia aquosa com desidratação e desequilíbrio eletrolítico. ${ }^{21}$

Observam-se o comprometimento do estado nutricional e carências vitamínicas múltiplas. A deficiência de vitamina $\mathrm{K}$ é 
comumente encontrada e, como consequência, ocorrem hemorragias cutâneas. Também pode ocorrer déficit de cálcio e hipocalcemia. ${ }^{22}$

A forma clássica continua sendo a manifestação clínica mais frequente da DC, 0 que vem reafirmar o que foi relatado nos estudos brasileiros realizados em 1980. Atualmente, tem sido observado o predomínio da forma clássica tardia, isto é, diagnosticada após os dois anos de idade, muito embora tenha ocorrido um aumento da forma não clássica em 32 dos pacientes estudados $(11,1 \%)$. $^{23}$

$\mathrm{Na}$ forma não clássica, ocasionalmente as manifestações digestivas estão ausentes ou ocupam um segundo plano. Sua apresentação ocorre mais tardiamente em crianças, sendo associada à distensão abdominal e edemas. Pode ocorrer retardo da puberdade (esterilidade), hipoplasia do esmalte dentário, anemia devido à má absorção de ferro e folato, epilepsia e calcificações intracraniana occipitais bilaterais. ${ }^{24}$

A forma assintomática ou silenciosa é comum em familiares de primeiro grau dos pacientes celíacos, e sua frequência tem aumentado nas últimas duas décadas, principalmente depois do desenvolvimento de marcadores sorológicos para a detecção da $D C$, especialmente os marcadores de anticorpos antigliadina, antiendomísio e antirreticulina ${ }^{14,25}$, facilitando, dessa forma, 0 diagnóstico da doença.

\section{EPIDEMiologia}

A prevalência populacional da DC varia muito de um país para outro, porém constitui uma desordem comum nos países europeus. A doença afeta um em cada 1.500 habitantes em toda a Europa. Recentemente, testes sorológicos constataram que, no
Reino Unido, a prevalência encontrada foi de um para cada 300 habitantes. Já na Europa e nos Estados Unidos, a prevalência foi entre $0,5 \%$ e $1,0 \% .26,20$

A frequência dessa doença tem sido demonstrada em crianças árabes, como os palestinos, kuwaitianos e jordanianos. Há registros de uma prevalência de um caso para $2.500,6.500$ e 2.800 pessoas respectivamente. Essa ocorrência provavelmente esteja relacionada a fatores genéticos e ambientais. Contudo, a alimentação também pode ser um fator importante no aumento dessa frequência, devido ao uso de alimentos que contém glúten. ${ }^{27}$

Um estudo realizado na Espanha com 3.378 crianças, constatou uma prevalência da DC silenciosa em $47,8 \%$ da população desse país. A relação entre a DC clássica e a silenciosa poderia relacionar-se com um importante alerta sobre a doença por parte dos profissionais da área da saúde. Um melhor conhecimento dos sintomas evitaria ou alto número de casos da DC não diagnosticada. ${ }^{28}$

No Uruguai, estudos epidemiológicos realizados demonstraram uma incidência de um caso em 200 nascimentos para a DC, o que, para uma população de 3 milhões e 200 mil habitantes, representaria um total de 1.600 indivíduos a manifestar a doença. Uma vez que a taxa de natalidade é de 56.000 nascimentos por ano, o esperado seria detectar cerca de 35 crianças potencialmente celíacas por ano. ${ }^{29}$

A incidência da DC no Brasil atinge uma frequência de 1 para cada 681 pessoas e demonstra que é relativamente comum em nosso país. ${ }^{30}$ Já no Chile, a prevalência oscilou de um caso em 1.700 a 2.000 nascidos vivos em 1994. Entretanto, na Argentina, observou-se uma prevalência de um caso no total de 167 pessoas, demonstrando que a frequência é alta no país. ${ }^{31,32}$ 


\section{Doenças Associadas}

Inúmeras doenças são associadas à DC, dificultando assim o diagnóstico. Entreelas, a dermatite herpetiforme, epilepsia, osteoporose, diabetes mellitus tipo 1 , síndrome de Down, deficiência de Imunoglobulina $A$ $(\lg A)$, entre outras. Muitas dessas doenças possuem uma base autoimune promovida pela prevalência do antígeno de histocompatibilidade (HLA-DR3 e DQ2) ${ }^{26}$

\section{Dermatite Herpetiforme}

A dermatite herpetiforme (DH) é uma enfermidade na qual surgem erupções pruriginosas, papulovesiculares em crianças e adolescentes. Ela afeta frequentemente as pernas, as nádegas, os joelhos e os ombros. A maioria dos pacientes com DH apresentam intolerância ao glúten, mas somentecerca de $10 \%$ dos portadores da DC manifestam essa enfermidade na pele. As manifestações na pele podem aparecer repentinamente ou aos poucos, sendo o prurido (coceira) o sintoma inicial e mais evidente. Em seguida, surge vermelhidão, urticária, além de vesículas e bolhas maiores que se rompem facilmente, devido à prática de coçar. Podem ser observadas também dores abdominais, diarréia e sensação de cansaço. ${ }^{33}$

\section{ANORMALIDADES ÓsSEAS}

Nos últimos anos, tem sido observado que a DC predispõe anormalidades ósseas, acarreta alterações no metabolismo do cálcio, resultando em osteomalácia, osteoporose e osteopenia. $\mathrm{Na}$ osteomalácia ocorre redução do conteúdo mineral do osso, sendo referida comumente como raquitismo do adulto. Já a osteoporoseé uma enfermidade metabólica óssea, caracteri- zada por uma baixa massa óssea e deterioramento na microestrutura desse tecido, levando a um aumento da fragilidade dos ossos, com consequente risco a fraturas e raquitismo (doença de bebês caracterizada por mineralização prejudicada do osso em crescimento, causada por deficiência de vitamina $D$, cálcio ou fósforo). A patogenia da osteopenia não está completamente esclarecida, no entanto o desenvolvimento de hipocalcemia por má absorção de cálcio é provavelmente o fator central que poderá desencadear outros distúrbios, particularmente em níveis el evados de paratormônio e reabsorção óssea. ${ }^{34}$

Tanto crianças quanto adultos apresentam uma diminuição da densidade mineral óssea e esta pode ser a principal manifestação da DC em ausência das manifestações gastrointestinais, o que resulta em considerar um diagnóstico diferencial de osteopenia/osteoporose, uma vez que tem se observado maior incidência de osteoporose em pacientes celíacos, sendo $25 \%$ maior do que em pacientes sadios. ${ }^{35}$

Os portadores de DC apresentam alta incidência de fraturas ósseas no esqueleto periférico. No caso dos portadores adultos, há um risco maior de desenvolver a densidade mineral óssea reduzida em relação a crianças e adolescentes. Alguns estudos realizados com pacientes na faixa etária pediátrica demonstram que a dieta isenta de glúten promove um aumento na densidade mineral óssea, entretanto, ainda é discutível sehá uma restituição completa dessa densidade com o tratamento. ${ }^{36}$

\section{Epilepsia e Calcificações Cerebelares}

A DC tem sido associada à epilepsia ecalcificações cerebelares, contudo essa associa- 
ção é rara e há poucos casos descritos mundialmente. Dentre estes, a maioria corresponde a pacientes originários da I tália, onde a incidência dessa doença é alta. A presença de calcificações estaria relacionada à baixa eficácia dos fármacos antiepilépticos e ao baixo seguimento da dieta sem glúten. Entretanto, esta diminuiria a frequência das crises epilépticas, tendo melhor eficácia quando diagnosticadas precocemente. A fisiopatologia da doença permanece incerta, porém há uma relação entre o déficit de ácido fólico secundário à má absorção e a formação de calcificações encefálicas. O utra hipótese seria a relação com o complexo de histocompatibilidade (HLA) no gene DQ2, localizado sobre cada um dos haplóides DR3/DR7 eDR5/ $D R$, sendo mais associado à predisposição à DC, a qual, na maioria dos pacientes italianos, encontra-se no DR3 heterozigotos. ${ }^{37}$

$\mathrm{Na}$ epilepsia, as crises podem ser parciais ou generalizadas, variando desde as facilmente controladas a casos refratários. As crises originadas no lobo occipital em pacientes celíacos são comuns. A relação entre calcificações e epilepsia não está totalmente estabelecida, uma vez quea evolução da epilepsia parece ser independente da existência das lesões occipitais. "A epilepsia pode ser uma manifestação precoce da doença e as calcificações cerebelares são processos que se desenvolvem mais tardiamente". Os mecanismos que levam às calcificações cerebelares permanecem incertos, sendo que a deficiência de ácido fólico foi também sugerida, entretanto, essa é uma das anormalidades bioquímicas mais comuns na DC. A dieta sem glúten é eficaz para o controle das crises epilépticas. Cabe ressaltar que, em muitos casos, os sintomas neurológicos podem constituir-se nas manifestações mais precoces e predominantemente em pacientes com formas atípicas da DC. ${ }^{38}$
Num estudo feito com um grupo de pacientes epilépticos e não epilépticos atendidos em dois hospitais de Brasília (DF) foram colhidas 255 amostras de soro de pacientes epilépticos ( 119 crianças e 136 adultos). 0 diagnóstico foi realizado por meio de anticorpos antiendomísio imunoglobulina A (EmA IgA) e de biópsia do intestino delgado, em que a prevalência encontrada foi de um para 127 pacientes epilépticos e de um para 293 no grupo de controle, cujos biópsia e teste EmA IgA foram positivos, constatando que a prevalência da DC foi de 2,3 vezes maior em pacientes epilépticos do que de controle. Apesar desse resultado não ser estatisticamente significativo, pode-se, em virtude dele, considerar altamente sugestiva a existência do aumento da DC em pacientes epilépticos. ${ }^{39}$

\section{Diabetes mellitus TiPo 1}

Aproximadamente $3,6 \%$ dos pacientes com diabetes mellitus tipo 1 apresentam DC, prevalência 20 vezes maior que na população sem esta patologia. A provável explicação para a ocorrência simultânea frequente é a suscetibilidade genética pela ação do antígeno de histocompatibilidade (HLA) DR3-DQ2.40

Nesses pacientes, os anticorpos antigliadina imunoglobulina A (AAG Ig A) possuem uma alta sensibilidade diagnosticada, no entanto há uma baixa especificidade, especialmente no início da doença diabética, em relação à disfunção imunológica que apresenta esses pacientes. Os anticorpos antiendomísio possuem larga especificidade, além do que observa-se resultados falsos positivos igualmente na fase crítica do diabetes. A DC pode aparecer em qualquer idade e em qualquer momento evolutivo do diabetes. Por outro lado, tem-se obser- 
vado casos de DC clássica com anticorpos antigliadina e antirreticulina positivos, na qual numa primeira biópsia normal recomenda-se incluir a determinação de marcadores sorológicos dessa doença no controle clínico dos pacientes com diabetes mellitus tipo1. Cabe mencionar também que a negatividade de um dos marcadores não exclui definitivamente o risco de contraí-la. ${ }^{41}$

Whitaker et. al. ${ }^{42}$ verificaram a associação entre diabetes melittus tipo 1 e DC em 195 pacientes. Por meio desse estudo observou-se que a prevalência da DC no grupo de pacientes com diabetes mellitus 1 foi de $4 \%$, sendo que os pacientes celíacos apresentaram predomínio de sintomas gastrintestinais, porém a presença de DC não interferiu no controle do diabetes.

\section{Diagnóstico}

Apesar dea biópsia intestinal permanecer como padrão ouro para o diagnóstico da DC, nos últimos anos muitos pesquisadores têm procurado testes menos invasivos que complementariam o diagnóstico no rastreamento e na monitorização da dieta sem glúten. Os principais marcadores sorológicos utilizados são os seguintes anticorpos: antigliadina (AGA), antirreticulina (ARA), antiendomísio (EMA) e transglutaminase tecidual (tTG), que são os mais recentes. ${ }^{43}$

\section{Prognóstico}

Os pacientes celíacos possuem maiores riscos de desenvolver linfomas malignos do que a população sadia. Entretanto, essa incidência diminui com a adesão estrita à dieta sem glúten, o que deve ser enfatizado no planejamento da dieta dos pacientes assintomáticos, que não se sentem forçados a seguir o tratamento por não manifestarem os sintomas da DC. ${ }^{44}$

Podem ocorrer complicações irreversíveis, como sucede nos casos das neoplasias. 0 adenocarcinoma do intestino delgado é considerado atualmente como uma das causas mais frequentes de degeneração maligna, depois do linfoma. Outros carcinomas, como os de língua, faringe, esôfago e estômago, possuem uma prevalência superior em celíacos em relação à população geral. ${ }^{45} 41$

A complicação maligna parece ser um problema principalmente da vida adulta, entretanto, há relatos de diagnóstico da DC em crianças na África, que após realizações de biópsias seriadas, as quais não apresentavam qualquer alteração na morfologia da mucosa intestinal com dieta sem glúten. No entanto, essas crianças, sete meses depois, apresentaram linfoma abdominal e, mesmo com sessões de quimioterapia, faleceram. ${ }^{46}$

\section{Cuidados Nutricionais}

0 único tratamento possível e eficaz para a DC, em todas as formas clínicas, é o dietético, devendo-se excluir o glúten da alimentação do paciente durante toda a sua vida, o que leva à remissão dos sintomas e restauração da morfologia normal da mucosa. 0 glúten, presente nos cereais, trigo, centeio, cevada e aveia, deve ser substituído pelo milho, arroz, batata emandioca, grãos, gorduras, óleos e azeites, legumes, hortaliças, frutas, ovos, carnes e leite, lembrando sempre que a dieta deverá atender às necessidades nutricionais de acordo com a idade do indivíduo. Além da dieta, o paciente celíaco deve estar atento também à composição dos medicamentos prescritos para ele. Quanto maior o grau de conhecimento da doença e de seu tratamento, maior a obediência à dieta desprovida de glúten. ${ }^{47}$ 
O glúten também pode estar presente como excipiente nas cápsulas, comprimidose suspensões orais de medicamentos. Esse fato pode limitar a plena obediência à dieta sem essa proténa, quando o paciente tiver a necessidade de utilizar algum medicamento dentre as múltiplas categorias medicamentosas existentes no mercado farmacêutico. Deve-se constituir uma preocupação a leitura das bulas, uma vez quea farinha de trigo éum ingrediente que pode passar despercebido na composição de muitos remédios. Alguns estudos realizados em 1990 observaram a presença de gliadina em $71,2 \%$ nos 59 medicamentos analisados nos Estados Unidos e em 31,9\% dos 47 medicamentos do estudo envolvido na I ugoslávia. No Brasil, foi realizado um estudo para detectar a presença de gliadina em medicamentos comercializados como: antiácidos, antibióticos, antidepressivos, antidiabéticos, anticonvulsivantes, entre outros. Como resultado, obteve-se que, dentre os 78 medicamentos analisados, apenas em 1,3\% foi detectada a presença de gliadina $(5,5 \mathrm{mg} / 100 \mathrm{~g})$. No entanto, não foi identificada nesses medicamentos uma quantidade que constituísse riscos aos pacientes com DC. ${ }^{48}$

A necessidade de esclarecer as causas e as manipulações dietéticas necessárias para o tratamento da DC aos pacientes e seus familiares mais próximos levou à criação das associações de celíacos. Em 1994, os pais dos portadores da DC fundaram a Associação dos Celíacos do Brasil (Acelbra), em São Paulo, cujos principais objetivos são: orientar os pacientes quanto à doença e à utilização da dieta sem glúten, além de divulgar essa enfermidade, alertando os médicos e a população em geral. ${ }^{49}$

\section{Conclusão}

As deficiências de vitaminas e minerais, desequilíbrio eletrolítico, anemia e doenças associadas, tais como: dermatite herpetiforme, diabetes mellitus tipo 1, epilepsia e anormalidades ósseas podem dificultar o restabelecimento do paciente celíaco e, ainda, comprometer o crescimento linear das crianças.

Com base nos critérios da Sociedade Européia de Gastroenterologia Pediátrica e Nutrição (ESPGAN) o diagnóstico da doença celíaca é realizado por meio de exames, como biópsias, com quais é possível observar alterações histológicas na mucosa do intestino delgado, na qual se observa particularmente atrofia das vilosidades.

A forma predominante da dessa enfermidade é a clássica, acometendo crianças entre seis a dezoito meses de idade. Além disso, alguns estudos no Brasil demonstram também um predomínio da forma clássica tardia, cujo diagnóstico ocorre após os dois anos de idade. Sendo assim, torna-se importante o estímulo ao monitoramento do desmame tardio, no qual as ações sejam voltadas a garantir que a introdução de alimentos com glúten seja feita com cautela. Considerando que o principal fator etiológico da doença celíaca é de natureza dietética, a adoção de práticas alimentares voltadas para a exclusão do glúten da dieta constitui medida profilática bastante eficaz. 0 seguimento de uma dieta sem glúten significa um desafio, uma vez que al gumas situações favorecem a ingestão involuntária dele.

Entretanto, cabe particularmente ao profissional nutricionista elaborar e orientar a terapia dietética e corrigir déficit nutricionais, excluindo o glúten e seus derivados da dieta. A Acelbra também é uma entidade muito relevante no intercâmbio e esclarecimento a respeito da doença celíaca, no sentido de difundir importantes informações. 


\section{REFERÊNCIAS BIBLIOGRÁFICAS}

1. Bongiovanni, TRS et al. Celiac Disease Impact of Gluten-free Camp on Quality of Life of Children and Adolescents with. Pediatrics. 2010;125(3):525-529.

2. Cottone $\mathrm{M}$, et al. Mortality and causes of death in celiac disease in a Mediterranean area. Digest Diseases Scienc. 1999; $44: 2538-2541$.

3. Kotze LMS. Celiac disease in brasilian patientes: associations, complications and causes of death. Forty years of clinical experience. Arq Gastroent. 2009;46(4):261-269.

4. Guevara GP. Enfermedad celíaca. Rev Chilena Pediat. 2002;73(4):394-397.

5. Melo FM et al. Associação entre marcadores sorológicos de doença celíaca e das doenças autoimunes da tireóide. Arq Bras Endoc Metab. 2005;49(4):543-5475.

6. Cummins, AG et al. Morphometric Evaluation of Duodenal Biopsies in Celiac Disease. Am J Gastroenterol. 106:145-150, 2011.

7. Siqueira-Neto JI, et al. Neurological manifestations of celiac disease. Arq Neurop, 2004;62(4):969-972.

8. Bobbio FO, Bobbio PA. Introdução à Química de Alimentos. 2 ed. São Paulo: Varela, 1995, p. 90-107.

9. Peña L, et al. Anticuerpos antitransglutaminasa nuevo test diagnóstico de la enfermedad celíaca. Canarias Pediátrica. 1999; 22: 17-20.

10. Morais MB, Sdepanian VL, Fagundes-Neto U. Doença celíaca. Rev Nutr Pauta. 2001; 51: 30-34.

11. Barta Z, Szab G, Szegedi G. Seroreactivity against saccharomyces cerevisiae in patients with crohn's disease and celiac disease. World J Gastroenter. 2003; 9: 2308-2312.

12. Pratesi R, et al. Prevalence of celiac disease: unexplained age-related variation in the same population. Scand Jl Gastroenter. 2003; 38: 747-750.

13. Fagundes-Neto, U. Doença celíaca. Disponível em URL: http://www.pediatria24horas.com.br/ congresso2.htm [2011 abril 13]

14. Sdepanian VL. Doença celíaca: exclusão de glúten. Nutr Saúde Perf. 2003; 21: 21-23.

15. Schafer AI, et al. Cecil: Tratado de Medicina Interna. 21 ed. v.1. Rio de Janeiro: Guanabara Koogan, 2001, p. 798-800.

16. Papadopoulos GK, Wijmenga C, Koning F. Interplay between genetics and the environment in the development of celiac disease: perspectives for a healthy life. The American Society for Clinical Investigation. 2001; 108: 1261-1266.

17. Gil-Humanes, J. Effective shutdown in the expression of celiac disease-related wheat gliadin T-cell epitopes by RNA interference. PNAS. 2010;107(39):17023-17028.

18. Guevara PG. Enfermedad celíaca. Rev Chil Ped. Santiago. 2002; 73: 394-397.

19. Monteleone, I. Celiac Disease Mucosa Characterization of IL-17A-Producing Cells in. J Immunol. 2010;184;2211-2218.

20. Van der Windt, D.A.W.M. et. al. Diagnostic testing for celiac disease among patients with abdominal symptoms - A Systematic Review. JAMA, May 5, 2010;303(17):1738-1746.

21. Fasano A, Catassi C. Current approaches to diagnosis and treatment of celiac disease: an envolving spectrum. American Assoc: Center for Celiac Research. 2001; 120: 36-651.

22. Barbieri D. Doença celíaca. In: MARCONDES E. Pediatria Básica. 8 ed. v. 2. São Paulo: Sarvier, 1999, p. 1186-1191.

23. Sdepanian Vl, Morais Mlb, Fagundes-Neto U. Doença celíaca: características clínicas e métodos utilizados no diagnóstico de pacientes cadastrados na Associação dos Celíacos do Brasil. Jornal Ped. 2001: 77: 131-138.

24. Khashan, AS et al. The impact of maternal celiac disease on birthweight and preterm birth: a Danish population-based cohort study. Human Reproduction, 2010;25(2):528-534.

25. Gonzales-Tarrio-Polo Lgt, Villace Cr, Val AA. Enfermedad celíaca: diagnóstico a partir de una paciente con clínica de dolor lumbar. Medifam. 2001;11: 97-99.

26. Ciclitira PJ. Technical review on celiac sprue. American Gastroenterologycal Association. 2001; 6: 15261540. 
27. Camps A, Zibetti S. Enfermedad celíaca y niños Saharawis. Anales Español Ped. 2001; 54: 89.

28. Pascual MLC, et al. Enfermedad celíaca silente: explorando el iceberg en población escolar. Anales Español Ped. 2002; 57: 321-326.

29. Favotto RC, et al. Alelos HLA_DQB e DRB asociados com la enfermedad celíaca em pacientes hospitalares. Rev Med Paraguai. 2001; 17: 107-113.

30. Sipahi AM, et al. Doença celíaca no adulto. Rev Bras Med. 2000; 57: 1254-1264.

31. Sánchez Ym, et al. Correlación entre los marcadores inmunológicos de la enfermedad celíaca y la atrofia de las vellosidades intestinales. Rev Cienc Tecnol Inv. 2000; 1: 67-71.

32. Weitz Jc, et al. Determinación de anticuerpos anti-transglutaminasa en el diagnóstico de enfermedad celíaca. Rev Med Chile. 2003; 131: 31-36.

33. Miravé JA, Jiménez CA. Enfermedad celíaca y outras causas de malabsorção. In: GARCIA PI, GARCIA GF, PRADOS AC, PÉREZ M, FUGAROLAS MG. Tratamiento de las Enfermedades Gastroenterológicas. Assoc Española Gastroenter: AEG, 2001, p. 433.

34. Silva GAP. Doença celíaca: repercussões na mineralização óssea. Jornal Ped. 2003; 79: 282-283.

35. Cerda RG, Rodrigues PC, Soto N, Munizaga F. Compromisso metabólico ósseo en enfermedad celíaca. Rev Méd Santiago. 2000; 3: 1-3.

36. Carvalho CNM, Sdepanian VL, Morais MB, Fagundes-Neto U. Doença celíaca em tratamento: avaliação da densidade mineral óssea. Jornal Ped. 2003;79(4):303-308.

37. Lausiuss GG, et al. Síndrome de enfermedad celíaca, calcificaciones y epilepsia. Archivos Pediát Uruguai. 2002; 73: 30-32.

38. Santos CHS, et al. Calcificação intracraniana occipital bilateral, epilepsia e doença celíaca. Arq Neurop. 2002;60(3B):840-843.

39. Pratesi R, et al. A prevalência da doença celíaca é elevada entre pacientes com epilepsia? Arq NeuroPsiquiatria. 2003b; 61: 330-334.

40. KunkeL N, Fiates GMR. Doença celíaca e dieta: uma revisão. Rev Nutr Brasil. 2003; 6: 373-379.

41. Ribes, C. K. Enfermedad celíaca: utilidad diagnostica de los marcadores serologicos, mitos y realidades. Rev Ciencia. 2002;2(29):1-18.

42. Whitacker, F.C.F. et al. Prevalência e aspectos clínicos da associação de diabetes melito tipo 1 e doença celíaca. Arq Bras Endoc Metabolismo. 2008;52(4):635-641.

43. Villalta, D. et al. IgG Antibodies against Deamidated Gliadin Peptides for Diagnosis of Celiac Disease in Patients with IgA Deficiency. Clinical Chem. 2010, 56(3):464-468.

44. Gotteland RM, Verbeke OS, Cruchet MS. Anticuerpos antitransglutaminasa tissular: una major prueba para detectar trangressiones menores de la dieta em pacientes celiacos? Rev Médica Chile. 2003;131: 25-29.

45. Landaburo RV, Pérez FS. Celiaquía: Nuevos rostros de una antigua enfermedad. Hospital Pediátrico José Luis Miranda, Santa Clara. 2002; 6:13-25.

46. Nakazato R, Fagundes-Neto U. Complicações malignas da doença celíaca. Elect J Ped Gastroent, Nutr Liver Diseases. 2002; 6: 15-22.

47. Rauen MS, Back JCV, Moreira EAM. Doença celíaca: sua relação com a saúde bucal. Rev Nutr, Campinas, 2005;18(2):271-76.

48. Sdepanian VL, et al. Pesquisa de gliadina em medicamentos: informação relevante para a orientação de pacientes com doença celíaca. Arq Gastroent. 2001;38(3):176-182.

49. Sdepanian VL, Morais MB, Fagundes-Neto U. Doença celíaca: características clínicas e métodos utilizados no diagnóstico de pacientes cadastrados na Associação dos Celíacos do Brasil. Jornal Pediat. 2001;77(2):131-138. 